\title{
Pectobacterium spp. Associated with Bacterial Stem Rot Syndrome of Potato in Canada
}

\author{
S. H. De Boer, X. Li, and L. J. Ward
}

Charlottetown Laboratory, Canadian Food Inspection Agency, 93 Mount Edward Road, Charlottetown, PE, C1A 5T1 Canada. Accepted for publication 14 June 2012.

\begin{abstract}
De Boer, S. H., Li, X., and Ward, L. J. 2012. Pectobacterium spp. associated with bacterial stem rot syndrome of potato in Canada. Phytopathology 102:937-947.

Pectobacterium atrosepticum, P. carotovorum subsp. brasiliensis, $P$. carotovorum subsp. carotovorum, and $P$. wasabiae were detected in potato stems with blackleg symptoms using species- and subspeciesspecific polymerase chain reaction (PCR). The tests included a new assay for $P$. wasabiae based on the phytase gene sequence. Identification of isolates from diseased stems by biochemical or physiological characterization, PCR, and multi-locus sequence typing (MLST) largely confirmed the PCR detection of Pectobacterium spp. in stem samples. P. atrosep-

detected in only $52 \%$ of the diseased stems. P. wasabiae was most frequently present in combination with $P$. atrosepticum and was the sole Pectobacterium sp. detected in $13 \%$ of diseased stems. Pathogenicity of $P$. wasabiae on potato and its capacity to cause blackleg disease were demonstrated by stem inoculation and its isolation as the sole Pectobacterium sp. from field-grown diseased plants produced from inoculated seed tubers. Incidence of $P$. carotovorum subsp. brasiliensis was low in diseased stems, and the ability of Canadian strains to cause blackleg in plants grown from inoculated tubers was not confirmed. Canadian isolates of $P$. carotovorum subsp. brasiliensis differed from Brazilian isolates in diagnostic biochemical tests but conformed to the subspecies in PCR specificity and typing by MLST.
\end{abstract} ticum was most commonly present but was the sole Pectobacterium sp.
Blackleg is a common and ubiquitous bacterial disease of potato. It is characterized by symptoms of decay and black discoloration of affected tissue that develops at the base of potato stems. Early in the growing season, underground stem decay results in stunted plants with stiff and yellowing foliage, which succumb within weeks of emergence, whereas blackleg that develops during midseason and thereafter manifests itself as decaying, black-colored stems with wilting or yellowing leaves. Affected stems usually become entirely decayed prior to crop maturity, dry out, and are obscured by the foliage canopy. Progeny tubers produced on diseased stems sometimes but not always become infected via the stolon and decay during the growing season or after harvest in storage. Lenticellular infection of progeny tubers also occurs from inoculum that spreads from decaying seed tubers into the root zones of affected plants.

In North America and Western Europe, the main causal agent of potato blackleg has been Pectobacterium atrosepticum (syn. Erwinia carotovora subsp. atroseptica), a gram-negative, motile bacterium physiologically and genomically similar to enteric bacteria associated with food spoilage and mammalian diseases but differing from them significantly in growth temperature optima and host preference. Although sometimes considered an opportunistic pathogen, $P$. atrosepticum has an intricate repertoire of genomic traits that equip it in a very special way for its coexistence and virulence on its host crop plant (9). Potato strains of $P$. atrosepticum exhibit a very limited degree of diversity, with the majority of strains typing into a single clade whether analysis is based on serology (10), biochemical tests (47), phage specificity (54), or molecular assays $(54,60)$.

Corresponding author: S. H. De Boer; E-mail address: solkedb@gmail.com

http://dx.doi.org/10.1094/PHYTO-04-12-0083-R

(c) 2012 Her Majesty The Queen in Right of Canada (Canadian Food Inspection Agency). All rights reserved. Use without permission is prohibited.
P. atrosepticum has also been implicated in diseases of various other crops besides potato such a tomato (32), pepper (50), sunflower $(2,17)$, and tobacco $(56)$. However, like the sugar beet pathogen, which was initially classified as E. carotovora subsp. atroseptica based on limited biochemical characterization (49), more extensive study revealed that, with some exceptions, nonpotato isolates differ from the potato blackleg pathogen (12). The decay-causing sugar beet strains were ultimately reclassified as $P$. betavasculorum $(18,52)$ but the taxonomic position of some of the other $P$. atrosepticum-like strains remains ambiguous.

Several reports from the United States and elsewhere suggested that $P$. carotovorum can also incite the blackleg disease, particularly under conditions of high field temperature $(33,34,43,48,51)$; and, recently, de Haan et al. (14) provided solid evidence, based on Koch's postulates, that certain strains of $P$. carotovorum indeed incite symptoms of blackleg in potato stems grown from inoculated seed tubers. Generally, however, most strains of $P$. carotovorum do not cause blackleg but are able to infect potato stems through wounds caused by insects, fungal infection, or farm implements during cultural maintenance of the crop. The symptoms of such stem infections, also known as aerial soft rot, are very different from those of blackleg in that they may turn various shades of brown but do not become inky black, as is common for the blackleg disease. A characteristic of the blackleg disease that differentiates it from aerial stem rot is that it originates belowground at the seed tuber and moves upward into the stem. Even though symptoms of blackleg may first break out at an aboveground node in the stem, infections can always be traced back through the vascular tissue or pith to the belowground portion of the stem, where the infection originated at the seed tuber. Aerial stem rot does not originate from the seed tuber although, in stems with advanced decay, differentiation between blackleg and aerial stem rot often becomes blurred.

Rather surprisingly, it was discovered recently that the potato blackleg disease in Brazil was not caused by $P$. atrosepticum but by a new subspecific clade within $P$. carotovorum which was 
tentatively named E. carotovora subsp. brasiliensis (currently $P$. carotovorum subsp. brasiliensis) (15). In fact, $P$. carotovorum subsp. brasiliensis appears to be the only causal agent of potato blackleg in Brazil because P. atrosepticum was not detected in an extensive survey of potato Pectobacterium spp. in the Brazilian state of Rio Grande do Sul (16). More recently, P. carotovorum subsp. brasiliensis was also identified as the major cause of potato blackleg in South Africa, where it has become a disease of significant economic importance (59). Strains of $P$. carotovorum subsp. brasiliensis grow at higher temperatures and are more virulent than $P$. atrosepticum strains (15), and clustered closer to $P$. carotovorum than $P$. atrosepticum in analyses based on biochemical characteristics (15) and housekeeping gene sequences (31). Because of its phylogenetic distinctiveness, it has been suggested that separate species status for $P$. carotovorum subsp. brasiliensis is warranted (19).

Another species of Pectobacterium, $P$. wasabiae, first described as causing soft rot of Japanese horseradish (23), was identified among Pectobacterium spp. isolated from decayed potato tubers in New Zealand $(39,40)$. These isolates not only caused tuber decay but also incited blackleg-like symptoms in stem-inoculated potato plants (40). Similarly, $P$. wasabiae was isolated from decayed potato tubers in the United States (Wisconsin) and Iran and similarly caused stem decay in potato plants inoculated for a virulence assay $(1,26)$. Although both the Wisconsin and Iranian strains of $P$. wasabiae caused decay of potato stem and tuber tissues upon inoculation, ability to cause the blackleg disease naturally by invasion of stem tissue from the seed piece has not yet been demonstrated.

In the early 1970 s, H. P. Maas Geesteranus found that potato stem rot in the Netherlands was sometimes caused by an unusual Erwinia-like bacterium that was ultimately identified as a Dickeya sp. (syn. E. chrysanthemi (H. P. Maas Geesteranus, personal communication). Although symptoms of this disease, known as "stengelnatrot" (stem wet rot) in the Netherlands, resembles potato blackleg, pith decay is more pronounced than in $P$. atrosepticum-caused blackleg during the early stages of the disease, and externally visible stem decay is less prevalent. At about the same time that stengelnatrot was recognized as a new disease in the Netherlands, a Dickeya sp. was also identified as the causal agent of a blackleg disease of potato in the Niigata prefecture of Japan (53) and tuber soft rot in the semiarid irrigated sands of southwestern New South Wales, Australia (3). Subsequently, the association of Dickeya spp. with potato disease was reported from France (41), Israel (30), and South Africa (43). Recently, Dickeya sp.-caused blackleg has become a major disease problem throughout Europe, including the Netherlands (6), France (24), Spain (36), Finland (29), and Poland (45), as well as in Israel, which imports seed potato from Europe $(57,58)$. The various biotypes of the previous E. chrysanthemi species have now been distributed among six Dickeya spp. but each of the species has been associated with potato disease. A newly described strain of Dickeya is of increasing economic importance as a cause of potato disease and, perhaps, warrants separate species status $(29,46)$. The name Dickeya solani has been proposed $(55)$.

Anticipated reduction in tuber-borne bacterial soft rot diseases with the introduction of pathogen-tested stem cuttings and aseptic tissue cultures for virus elimination in seed potato programs has only been partially realized $(21,62)$. Although some reduction in disease occurred $(8,20,22)$, blackleg continues to plague the industry and, according to observations by industry stakeholders and anecdotal accounts, is actually increasing again in some regions of Europe and North America. These observations were the impetus to reevaluate the etiology of blackleg and stem rot of potato in Canada using molecular diagnostic tools not previously available. The objective of this study was to ascertain whether or not $P$. atrosepticum was still the primary cause of blackleg, as has been the case, or whether the potato industry was faced with a changing scenario in which different Pectobacterium spp. contributed to a more complex bacterial stem rot syndrome.

\section{MATERIALS AND METHODS}

Bacterial strains, media, isolation, maintenance, and characterization. Reference strains for the different Pectobacterium taxa used in this study were as follows: $P$. atrosepticum strain 3 and 31 (11); P. carotovorum subsp. carotovorum strain 26 and 71 (11); P. carotovorum subsp. brasiliensis strains 8, 212, and 371 (15); and P. wasabiae SR94 (23). These strains were from the laboratory collection maintained in $20 \%$ glycerol at $-80^{\circ} \mathrm{C}$ and were grown routinely on nutrient agar. New isolates of Pectobacterium spp. were obtained from diseased potato stems and tubers by selecting colonies that developed pits in crystal violet pectate (CVP) medium (4) and visually resembled Pectobacterium colony morphology when viewed with a dissecting microscope using oblique illumination. Colonies picked from CVP medium were plated on casamino acid-peptone-glucose or nutrient agar medium to obtain pure cultures, and were maintained in $20 \%$ glycerol at $-20^{\circ} \mathrm{C}$. Biochemical or physiological tests to differentiate Pectobacterium isolates, including ability to grow at $36^{\circ} \mathrm{C}$, production of acid from $\alpha$-methylglucoside, production of reducing substances from sucrose, and phosphatase activity, were routinely carried out on fresh cultures using reference strains as controls according to standard published procedures (42).

Potato samples. Samples of potato stems expressing blackleglike symptoms and associated tubers with decay were sent to the laboratory by various collaborators in the Canadian provinces of Alberta, Saskatchewan, Manitoba, and Prince Edward Island. Upon receipt, samples were processed immediately or kept at $-20^{\circ} \mathrm{C}$ until processed. For each sample, 0.5 to $1.0 \mathrm{~g}$ of diseased tissue, where possible at the interface with healthy tissue, was macerated in $1 \mathrm{ml}$ of distilled water in an extraction bag (BioReba, Reinach, Switzerland). Liquid from the bag (1 ml) was used for extracting DNA (referred to as sample DNA hereafter) using a KingFisher magnetic particle processor (Thermo Fisher Scientific Inc., Toronto). For some of the samples, a separate aliquot was directly plated on CVP medium, or plated after incubation for 3 to 4 days in enrichment broth at room temperature (42), for isolation of Pectobacterium spp. Symptomatic stems from field trials were sampled in the same way, whereas asymptomatic tubers from field trials were tested by removing $0.5 \mathrm{~g}$ of tissue from the stolon end and macerating the tissue in extraction bags using a Homex 6 homogenizer (BioReba).

Polymerase chain reaction of sample DNA. Conventional polymerase chain reaction (PCR) using taxon-specific primers (Table 1) was used to determine which Pectobacterium spp. or subspecies were present in individual plant samples. PCR was performed with Sprint Advantage Single Shot (Clontech, Mountain View, CA) reagents and primer concentrations of $0.5 \mu \mathrm{M}$. After denaturation for $5 \mathrm{~min}$ at $95^{\circ} \mathrm{C}, 40$ cycles were run at $95^{\circ} \mathrm{C}$ for $30 \mathrm{~s}, 62^{\circ} \mathrm{C}$ for $30 \mathrm{~s}$ (except $60^{\circ} \mathrm{C}$ for primer set $\mathrm{PhF} / \mathrm{PhR}$ ), and $72^{\circ} \mathrm{C}$ for $30 \mathrm{~s}$, followed by a final extension at $72^{\circ} \mathrm{C}$ for $4 \mathrm{~min}$. PCR products were analyzed by capillary gel electrophoresis (Qiagen, Mississauga, ON, Canada) or electrophoresis in $1 \%$ agarose gels.

Development of a PCR assay for $\boldsymbol{P}$. wasabiae. A PCR assay was developed for $P$. wasabiae based on the GenBank sequence (EU203663) of the novel phytase gene, appA, that had been cloned and sequenced from the type strain (DSMZ18074 = SR91) (44). Primers were selected using Allelle ID software (Premier Biosoft, Palo Alta, CA). Specificity of the PCR assay was based on the failure to obtain amplification products from known non-P. wasabiae isolates of Pectobacterium and uniqueness of the DNA sequence determined in BLAST analysis of the GenBank nucleotide database. A preliminary report has been published (61). 
PCR and multi-locus sequence typing identification of isolates. Pure cultures of isolates provisionally identified by biochemical and physiological tests were further characterized by PCR using taxon-specific primers as indicated above for sample DNA. Additionally, isolates were characterized by multi-locus sequence typing (MLST) targeting either two or six housekeeping genes (acnA, gapA, icdA, $m d h, p g i$, and proA), as described by Ma et al. (31). When all six genes were included, both concatenated and individual sequences were aligned and analyzed using AlignPlus 4 (version 4.1) of Clone Manager Professional Suite with default settings along with a collection of comparable sequences of $\mathrm{Ma}$ et al. (31) retrieved from GenBank. Routinely, identity of isolates was confirmed by sequencing only the acnA and proA gene fragments and determining their phylogenetic affinities based on the associated clade when compared and analyzed with a collection of homologous GenBank sequences.

Pathogenicity testing. Maceration ability of isolates was determined in both green pepper fruit and potato tubers. Green pepper fruit from a local grocer were surface sterilized with $1 \%$ commercial bleach and $70 \%$ ethanol, thoroughly rinsed before being cut longitudinally, and inoculated with Pectobacterium isolates using a toothpick dipped into a colony of a 48-h-old bacterial culture. The diameter of decay surrounding the inoculation point was measured $48 \mathrm{~h}$ after incubation of inoculated pepper at $23^{\circ} \mathrm{C}$. Potato tubers were similarly surface sterilized and inoculated with Pectobacterium spp. using the same toothpick method, and covered with a thin film of mineral oil. After $72 \mathrm{~h}$, tubers were cut through the middle of inoculation sites and the diameter of decay was measured at the widest point.

To determine stem-rotting ability, stems of 8-week-old greenhouse-grown potato plants (two each of 'Fabula', 'Norland', 'Superior', and 'Yukon Gold') were inoculated at lower leaf axils with toothpicks dipped into bacterial colonies. Plants were inoculated individually with five isolates of $P$. atrosepticum, six isolates of $P$. carotovorum subsp. brasiliensis, and four isolates each of $P$. carotovorum subsp. carotovorum and $P$. wasabiae. Symptoms of decay and leaf wilting were rated separately on a scale of 0 to $5(0=$ no symptoms and $5=$ decay causing stem collapse or wilt of all leaves) over a 12-day period. Disease index was calculated as the sum of the decay and wilt ratings. The stem inoculation experiment was repeated on a set of six greenhousegrown plants (Superior) per Pectobacterium taxon.

Field trials. Ability of isolates of the different Pectobacterium taxa to cause blackleg-like disease was tested in field plots using inoculated seed tubers to simulate a natural pathway of infection. Surface sterilized, high-class (Elite I) seed potato tubers (Superior) were vacuum infiltrated with suspensions of bacterial isolates obtained in this study, diluted $1 / 1000$ in water from suspensions adjusted to an optical density at $600 \mathrm{~nm}$ of 1.0 , and air dried. In 2010, tubers were inoculated 1 week before planting. At planting, tubers were cut into seed pieces and immediately planted by treatment in six rows $1 \mathrm{~m}$ apart. Each treatment (consisting of 20 seed tubers/subplot) was situated randomly within the plot and flanked within rows by unplanted 5-m spaces. The $P$. atrosepticum (three isolates), P. wasabiae (three isolates), $P$. carotovorum subsp. brasiliensis (two isolates), and $P$. carotovorum subsp. carotovorum (two isolates) treatments as well as a water control treatment were replicated five times within the plot. The same plot layout was duplicated in an irrigated and an unirrigated field. In the irrigated field, irrigation was applied to supplement rainfall as required to maintain high soil moisture at all times. Cultivation, fertilization, and pesticide applications conformed to local commercial potato-growing practices.

In 2011, a similar field plot was established with potato tubers (Superior) inoculated the same way as in 2010 but planted 3 weeks after inoculation. Plot layout was similar to that used in 2010 except that all replications of each treatment were in adjacent rows, separated from other treatments by control waterinoculated subplots, and flanked within rows by unplanted $5-\mathrm{m}$ spaces. Each of two strains of each species or subspecies were considered a treatment and replicated in five subplots within the plot. As in 2010, duplicate plots were planted for an irrigated and an unirrigated trial; plots were again managed in conformance to local commercial practices.

In both the 2010 and 2011 field trials, incidence of blackleg disease was monitored weekly and a few symptomatic plants were collected during the growing season for testing by PCR using taxon-specific primers. Isolations were made from some of the diseased stems in 2011. Plants were chemically top killed 97 and 91 days after planting in 2010 and 2011, respectively, and harvested 19 and 13 days after top-kill application, respectively. At harvest, tubers were taken randomly from some of the plots to test for latent infections with Pectobacterium spp. Tubers were tested by processing 0.5 -g tissue samples from the stolon ends as described above and tested individually or combined into composites of 5 or 10 samples before testing by PCR using taxonspecific primers.

\section{RESULTS}

PCR detection of Pectobacterium spp. in blackleg-infected potato stems. Samples of potato stems with blackleg symptoms were received from 30 different commercial potato fields in 2007 to 2009 (Table 2). P. atrosepticum was detected by PCR in samples from $90 \%$ of the fields. $P$. wasabiae and $P$. carotovorum subsp. brasiliensis were also detected in 37 and $7 \%$ of the fields, respectively. Although the PCR for P. carotovorum subsp. carotovorum was also positive for $23 \%$ of the fields, the primers used had poor specificity for the subspecies, amplifying some strains of $P$. wasabiae (25) and not amplifying all strains of $P$. carotovorum subsp. carotovorum.

P. atrosepticum was detected in $86 \%$ of the individual stems with blackleg symptoms (Table 2) but was the only Pectobacterium sp. detected in $52 \%$ of them. P. wasabiae was the second most common Pectobacterium sp. detected, being found in $36 \%$ of symptomatic stems, and the sole Pectobacterium sp. detected

TABLE 1 . Nucleotide sequence of taxon-specific primers used in this study

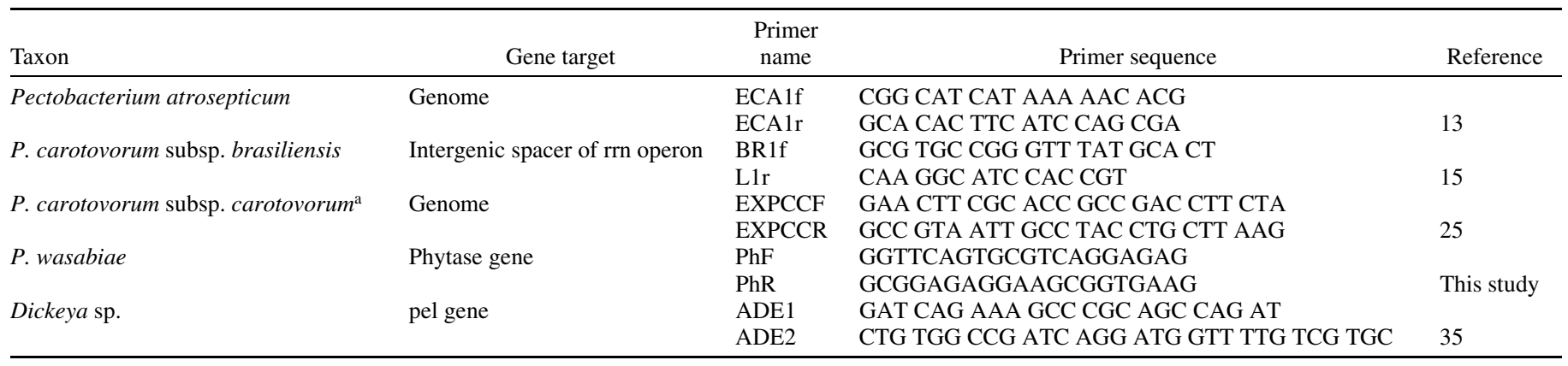

${ }^{\text {a }}$ Known to also amplify some $P$. wasabiae strains (25). 
in $13 \%$ of individual stems. $P$. carotovorum subsp. brasiliensis and $P$. carotovorum subsp. carotovorum were detected at lower incidences (Table 2) and never as the sole Pectobacterium sp. present.

Isolation of Pectobacterium spp. from blackleg-infected stems was attempted and successful for only some of the stems from the commercial field sources. In every case, the species or subspecies of Pectobacterium isolated had been detected by PCR in sample DNA, with only one exception, in which $P$. carotovorum subsp. brasiliensis was isolated but had not been detected by PCR.

Isolation and characterization of Pectobacterium isolates. Isolation from diseased potato stems yielded 30 isolates. An additional six isolates were obtained from decayed potato tubers submitted separately to the laboratory. Good correlation was obtained between the different methods used to identify the isolates, which included biochemical characterization, PCR using taxonspecific primers, and MLST (Table 3). Two pectin-degrading isolates having phosphatase activity and whose DNA was amplified in PCR using the Dickeya spp-specific primers were presumptively identified as Dickeya spp. and not tested further in this study. Consistent with the frequency at which $P$. atrosepticum was detected by PCR in diseased stems, most of the isolates $(63 \%)$ were identified as $P$. atrosepticum by their biochemical and physiological characteristics (Table 3). P. wasabiae strains were differentiated from $P$. carotovorum strains by their inability to grow at $36^{\circ} \mathrm{C}$ and their identities confirmed by results of the taxon-specific PCR and MLST. The isolates identified as $P$. carotovorum subsp. brasiliensis reacted as $P$. carotovorum subsp. carotovorum strains in the differential biochemical tests in contrast to the control Brazilian strain (Table 3). However, these isolates were deemed to be $P$. carotovorum subsp. brasiliensis on the basis of DNA amplification in the taxon-specific PCR and MLST.

Initial identification using MLST was by the method of Ma et al. (31), in which sequences of six gene fragments were concatenated and sorted into clades within a dendrogram. Grouping of unknown strains into the clades identified by Ma et al. (31) was taken as evidence of isolate identity. Housekeeping gene sequences were also analyzed separately and found, with few exceptions, to group strains in the same way as the concatenated gene sequences. Hence, two housekeeping genes, proA and $a c n A$, were selected for routine sequencing and analysis to rapidly identify new isolates (Fig. 1). Some strains of each Pectobacterium taxon were identified by MLST using concatenated sequences but, subsequently, new isolates were identified by analysis of only the two genes.

Identification of older Pectobacterium isolates in a culture collection. To determine whether the recent detection of $P$. carotovorum subsp. brasiliensis and $P$. wasabiae on potato is a new phenomenon or an artifact engendered by better methods for recognizing unusual genotypes, Pectobacterium spp. collected by one of us (S. H. De Boer) as E. carotovora strains from various researchers during 1970 to 1985 were recharacterized by PCR and MLST. Interestingly, a few strains from both New and Old World sources were identified as $P$. carotovorum subsp. brasiliensis and a few strains from the United States as $P$. wasabiae (Table 4).

Virulence testing of Pectobacterium isolates. The selection of Pectobacterium isolates obtained in this study and tested for maceration ability included two strains of $P$. atrosepticum, three of $P$. wasabiae, four of $P$. carotovorum subsp. brasiliensis, and two of $P$. carotovorum subsp. carotovorum. All isolates tested caused soft rot lesions at the point of inoculation of green pepper fruit and potato tubers. Although the amount of maceration incited by the $P$. atrosepticum and $P$. wasabiae strains (mean diameter of decay in potato $=17 \mathrm{~mm}$ ) was, on average, less than decay incited by $P$. carotovorum subsp. brasiliensis and $P$. carotovorum subsp. carotovorum strains (mean diameter of decay $=$ 20 and $21 \mathrm{~mm}$, respectively), the difference was not statistically significant due, in part, to the variability among strains within taxa. In contrast, virulence of $P$. atrosepticum and $P$. wasabiae strains tended to exceed that of $P$. carotovorum subsp. brasiliensis and $P$. carotovorum subsp. carotovorum when inoculated into potato stems (Fig. 2). The characteristics of the decay lesions on stems and pattern of leaf wilting, except for their severity, were similar among those induced by the different Pectobacterium spp. and subspecies.

Analysis of Pectobacterium spp. infecting potato plants and tubers grown from inoculated seed tubers in field trials. The incidence of blackleg and stem rot disease that developed in

TABLE 2. Number of different field sources from which stem samples with blackleg symptoms were obtained and the Pectobacterium taxa detected therein, and number of individual stems tested from those sources and Pectobacterium taxa detected in the individual stems during 2007-2009

\begin{tabular}{|c|c|c|c|c|c|c|c|c|c|c|}
\hline \multirow[b]{2}{*}{ Year } & \multicolumn{5}{|c|}{ Field sources } & \multicolumn{5}{|c|}{ Individual stems } \\
\hline & Total & $\mathrm{Pa}$ & $\mathrm{Pw}$ & Pcbr & Pcc & Total & $\mathrm{Pa}$ & $\mathrm{Pw}$ & Pcbr & Pcc \\
\hline 2007 & 11 & 10 & 1 & 1 & 2 & 17 & 11 & 5 & 1 & 1 \\
\hline 2008 & 7 & 7 & 2 & 0 & 4 & 30 & 30 & 2 & 0 & 6 \\
\hline Total & 30 & $27(90 \%)$ & $11(37 \%)$ & $2(7 \%)$ & $7(23 \%)$ & 90 & $77(86 \%)$ & $32(36 \%)$ & $4(4 \%)$ & $11(12 \%)$ \\
\hline
\end{tabular}

${ }^{\text {a }} \mathrm{Pa}=$ Pectobacterium atrosepticum, $\mathrm{Pw}=P$. wasabiae, $\mathrm{Pcbr}=P$. carotovorum subsp. brasiliensis, and $\mathrm{Pcc}=$ P. carotovorum subsp. carotovorum.

TABLE 3. Characteristics of Pectobacterium isolates from blackleg-infected potato stems and associated tubers with decay lesions

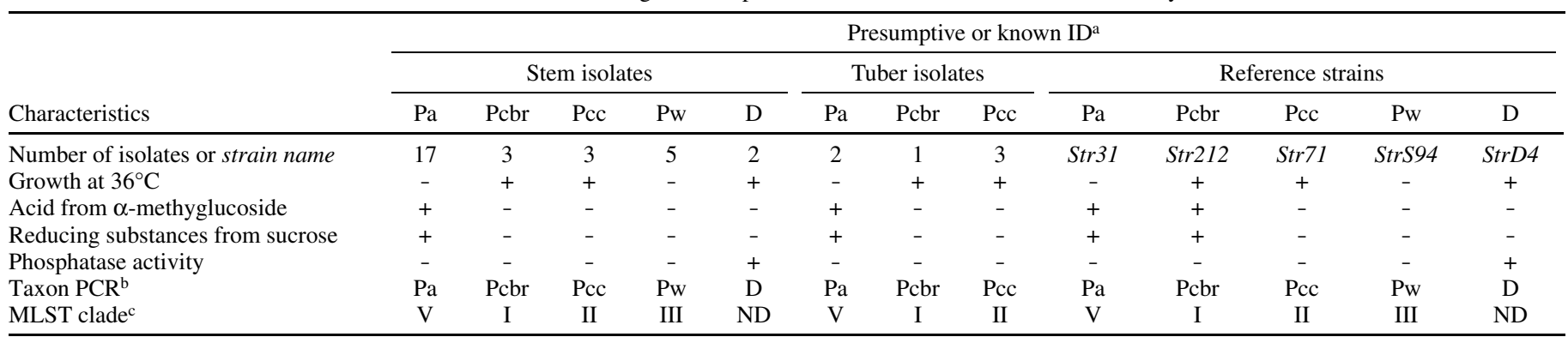

a $\mathrm{Pa}=$ Pectobacterium atrosepticum, $\mathrm{Pcbr}=P$. carotovorum subsp. brasiliensis, $\mathrm{Pcc}=P$. carotovorum subsp. carotovorum, $\mathrm{Pw}=P$. wasabiae, and $\mathrm{D}=$ Dickeya $\mathrm{sp}$.

${ }^{\mathrm{b}}$ Positive polymerase chain reaction (PCR) amplification with indicated taxon-specific primer pair.

${ }^{\mathrm{c}}$ MLST = multi-locus sequence typing. Cluster identity in phylogenic dendrogram based on housekeeping gene sequences sensu Ma et al. (31); ND designates not done. 
plants grown from inoculated seed potato was greater in 2011 than in 2010, probably because of the high rainfall during the 2011 growing season (Table 5). In both years, the incidence of disease was greater in the irrigated than the unirrigated plots. Because disease incidence in many of the treatments was low, data from all treatments inoculated with the same species or subspecies were combined (Table 5). Overall incidence of blackleg-like symptoms was greatest in $P$. atrosepticum treatments, followed by $P$. wasabiae. Plots with $P$. carotovorum subsp. brasiliensis and $P$. carotovorum subsp. carotovorum treatments had low incidence of disease in both the 2010 and 2011 field trials. Disease symptoms were not distinguishably different among plants in the different treatments.

Multiple Pectobacterium spp. were detected by taxon-specific PCR in most diseased stems collected from the 2010 field plot. The presence of noncorresponding Pectobacterium spp. (i.e.,

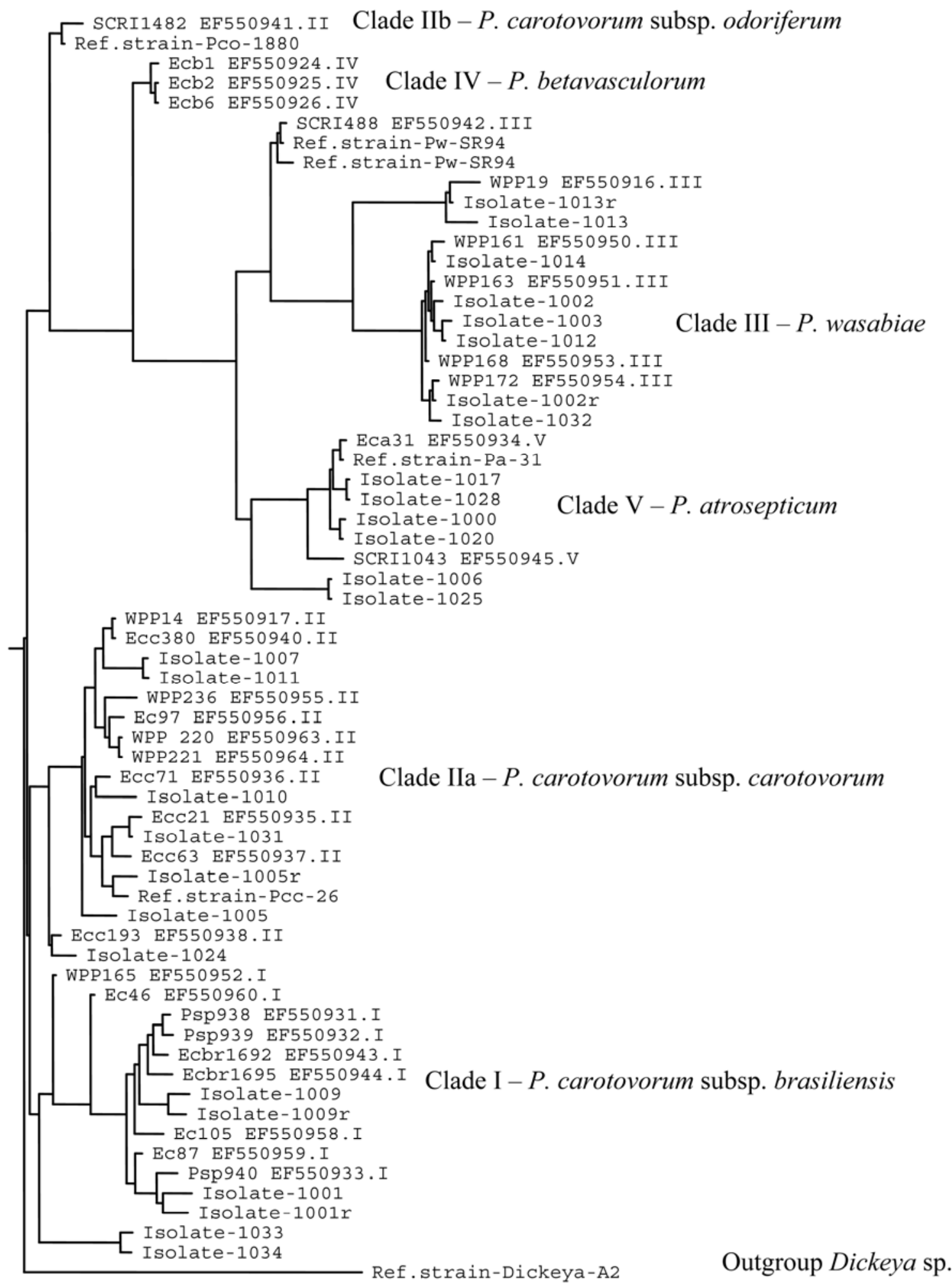

Fig. 1. Neighbor-joining cladogram based on proA gene sequences. Sequences obtained from GenBank identified by strain and accession numbers followed by clade designation sensu Ma et al. 2007 (31). Isolates designated with " $\mathrm{r}$ " indicate data based on replicate sequencing experiment to validate robustness of clustering of strains based on unedited sequence data. 
Pectobacterium spp. not inoculated in the treatment) in diseased stems from all treatments probably resulted from aerial spread of bacteria from diseased plants in adjacent plots; however, the possibility of other sources of inoculum such as the seed tubers cannot be excluded, although no Pectobacterium spp. could be detected by PCR in seed tuber sample extracts. In any case, for this reason, treatments were not randomized in the 2011 field trial but, rather, each treatment was surrounded by unplanted spaces and separated by a control treatment. All diseased stems tested from $P$. atrosepticum-inoculated tubers in both the irrigated and unirrigated 2011 trial were positive in the PCR assay for P. atrosepticum and negative in the assay for all the other Pectobacterium spp., except for one stem that was also positive for $P$. carotovorum subsp. carotovorum (Table 6). Of the 25 tested diseased stems grown from $P$. wasabiae-inoculated tubers, 22 were positive in the PCR for $P$. wasabiae and negative in the PCR assays for $P$. atrosepticum and $P$. carotovorum subsp. brasiliensis (Table 6). The positive reaction of the 15 stems in the P. carotovorum subsp. carotovorum PCR assay can be attributed to the cross-amplification of $P$. wasabiae in this assay. The negative PCR reaction of the five diseased stems from the $P$. wasabiae treatment is likely caused by PCR inhibitors in the DNA extracts. Few plants grown from $P$. carotovorum subsp. brasiliensis-inoculated seed developed disease, and the subspecies was detected in only three of the eight diseased stems tested (Table 6). However, these stems were also negative in the PCR for the other Pectobacterium spp. One of the four diseased stems tested from the $P$. carotovorum subsp. carotovorum treatment was positive in the $P$. atrosepticum-specific PCR assay but the likely causal agent of the disease in the other stems, being negative in the other PCR assays, was not ascertained (Table 6).

$P$. wasabiae was successfully isolated from diseased stems of plants grown from seed tubers inoculated with each of the two isolates. However, P. carotovorum subsp. brasiliensis could not be isolated from corresponding diseased stems even though its presence was detected in the taxon-specific PCR assay, perhaps because the stems were stored for several months at $-20^{\circ} \mathrm{C}$ prior to attempting isolation. No attempt was made to isolate Pectobacterium spp. from diseased stems of the $P$. atrosepticum and $P$. carotovorum subsp. carotovorum treatments.

$P$. atrosepticum and $P$. wasabiae were detected by taxonspecific PCR in at least one composite sample of progeny tubers harvested from corresponding plots in the 2010 unirrigated field trial. Similarly, $P$. carotovorum subsp. brasiliensis and $P$. wasabiae but not $P$. atrosepticum was detected in at least one composite tuber sample from corresponding plots in the 2011 unirrigated field trial. $P$. atrosepticum, $P$. carotovorum subsp. brasiliensis and $P$. wasabiae were all detected in corresponding

TABLE 4. Reidentification of Pectobacterium carotovorum strains in a laboratory culture collection of Pectobacterium spp. isolated during 1970-1985

\begin{tabular}{|c|c|c|c|c|}
\hline \multirow[b]{2}{*}{ Geographic origin of strains } & \multirow[b]{2}{*}{ Number of strains } & \multicolumn{3}{|c|}{ Number of strains identified per taxon ${ }^{a}$} \\
\hline & & P. carotovorum subsp. carotovorum & P. carotovorum subsp. brasiliensis & P. wasabiae \\
\hline British Columbia, Canada & 46 & 44 & 2 & 0 \\
\hline Oregon, United States & 26 & 23 & 2 & 1 \\
\hline Other states, United States & 7 & 6 & 0 & 1 \\
\hline Scotland & 31 & 28 & 3 & 0 \\
\hline The Netherlands & 36 & 35 & 1 & 0 \\
\hline
\end{tabular}

${ }^{a}$ Strains identified on basis of taxon-specific PCR and confirmed by multi-locus sequence typing for strains identified as $P$. carotovorum subsp. brasiliensis and $P$. wasabiae.

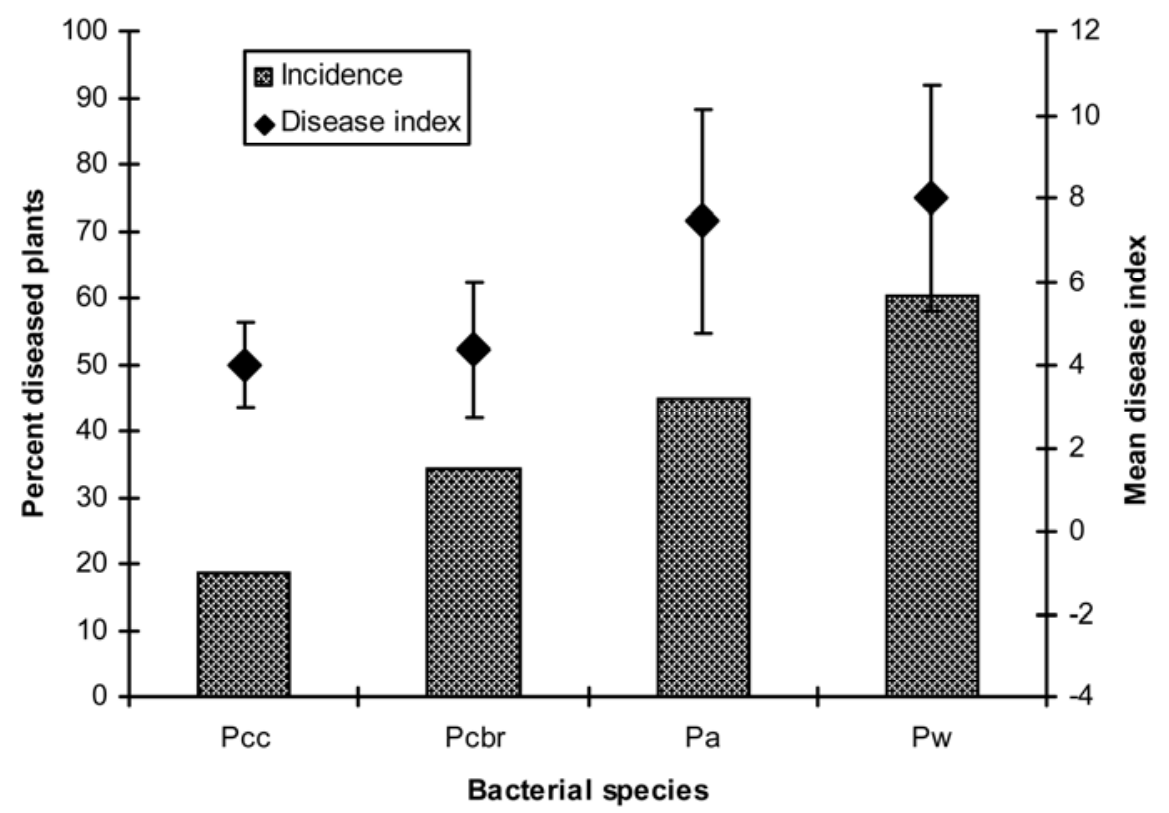

Fig. 2. Disease development in stem-inoculated, greenhouse-grown potato plants indicated by incidence as percentage of plants developing symptoms (disease index >2) and disease severity as the mean of disease index of diseased plants only at 11 days after inoculation. Data points based on inoculations of two plants of each of four potato cultivars ('Fabula', 'Norland', 'Superior', and 'Yukon Gold') for two strains of Pectobacterium carotovorum subsp. carotovorum (Pcc) ( $n=$ 16), four strains of $P$. carotovorum subsp. brasiliensis $(\mathrm{Pcbr})(n=32)$, five strains of $P$. atrosepticum $(\mathrm{Pa})(n=40)$, and six strains of $P$. wasabiae $(\mathrm{Pw})(n=48)$. Disease index (0 to 10) is the sum of scores for decay and for wilting each based on a scale from 0 (no decay or wilt) to 5 (extensive decay or wilt). 
composite tuber samples from irrigated plots of both 2010 and 2011. P. carotovorum subsp. brasiliensis was detected in at least one composite sample of noncorresponding composite tuber samples from irrigated plots of both 2010 and 2011, except from the $P$. atrosepticum-inoculated treatment in 2010. $P$. carotovorum subsp. brasiliensis was also detected most frequently in PCR assays of individual tuber samples from the 2010 irrigated plot, although $P$. atrosepticum and $P$. wasabiae were also detected in tubers from noncorresponding treatments (Table 7). To be sure that the apparent widespread presence of $P$. carotovorum subsp. brasiliensis in progeny tubers was not a PCR artifact, the PCR result was confirmed for two samples by sequencing the PCR amplicon and for three samples by isolation of the bacterium. PCR tests for $P$. carotovorum subsp. carotovorum were not done on progeny tuber samples.

\section{DISCUSSION}

The number of species and subspecies of Pectobacterium has increased over recent years and, as a result, their identification and differentiation by classical microbiological tests has become increasingly challenging. Previously, $P$. atrosepticum and $P$. carotovorum were the most frequently encountered species in soft rot disease of plants and were readily distinguished by whether they grew at $36^{\circ} \mathrm{C}$ and whether or not they could produce acid from $\alpha$ methylglucoside and reducing substances from sucrose. With the recognition of additional species and subspecies, including $P$. betavasculorum, $P$. wasabiae, $P$. carotovorum subsp. brasiliensis, and $P$. carotovorum subsp. odoriferum, it has become more difficult to make accurate identifications based on biochemical tests alone because carbohydrate utilization patterns and other phenotypic characteristics vary among strains of the same species or subspecies. However, the differentiation of Pectobacterium spp. by MLST into clades which closely correspond to described species and subspecies (31) provides a convenient means for determining or confirming the affiliation of new isolates. The rapidity and low cost of DNA sequencing makes MLST a good alternative to classical determination of physiological and biochemical characteristics for bacterial identification. Our results indicated that complete MLST analysis on multiple concatenated gene sequences was unnecessary to identify isolates, because sequence analysis of even a single housekeeping gene provided good identification when evaluated in combination with an adequate number of selected GenBank sequences of the same gene to define the Pectobacterium spp. and subspecies. However, to insure correct identification, we preferred to sequence at least two housekeeping genes to identify new isolates. The strategy of using housekeeping gene sequences for identifying new isolates of Pectobacterium spp. and the closely related Dickeya spp. from potato has also already been used by other researchers $(1,37,39)$.

Molecular techniques have not only contributed to the facile and rapid identification of bacterial isolates but their use as

TABLE 5. Incidence of blackleg-like symptoms in potato plants ('Superior') grown in field plots from seed tubers inoculated by vacuum infiltration with cultures of Pectobacterium atrosepticum, $P$. carotovorum subsp. carotovorum, P. carotovorum subsp. brasiliensis, $P$. wasabiae, or sterile distilled water

\begin{tabular}{lcccccc}
\hline & & \multicolumn{5}{c}{ Plants with blackleg symptoms (\%) per seed tuber inoculant } \\
\cline { 3 - 7 } Year & Irrigation & P. atrosepticum & P. carotovorum subsp. brasiliensis & P. carotovorum subsp. carotovorum & P. wasabiae & Water \\
\hline 2010 & No & 4 & 3 & 0 & 1 \\
2010 & Yes & 13 & 5 & 2 & 0 & 0 \\
2011 & No & 36 & 5 & 3 & 0 & 11 \\
2011 & Yes & 47 & 1 & 5 & 0 \\
\hline
\end{tabular}

TABLE 6. Pectobacterium spp. and subspecies detected by taxon-specific polymerase chain reaction (PCR) in diseased stems of potato plants grown in a field trial from inoculated seed tubers during 2011

\begin{tabular}{|c|c|c|c|c|c|}
\hline \multirow[b]{2}{*}{ Inoculated taxon } & \multirow[b]{2}{*}{$\begin{array}{l}\text { Number of } \\
\text { stems tested }\end{array}$} & \multicolumn{4}{|c|}{ Number of stems positive in $\mathrm{PCR}^{\mathrm{a}}$} \\
\hline & & $\begin{array}{l}\text { Pectobacterium } \\
\text { atrosepticum }\end{array}$ & $\begin{array}{l}\text { P. carotovorum subsp. } \\
\text { brasiliensis }\end{array}$ & $\begin{array}{l}\text { P. carotovorum subsp. } \\
\text { carotovorum }^{\mathrm{b}}\end{array}$ & P. wasabiae \\
\hline \multicolumn{6}{|l|}{ Unirrigated trial } \\
\hline P. carotovorum subsp. brasiliensis & 4 & 0 & 1 & 0 & 0 \\
\hline P. carotovorum subsp. carotovorum & 2 & 1 & 0 & 0 & 0 \\
\hline P. wasabiae & 13 & 0 & 0 & 8 & 11 \\
\hline P. carotovorum subsp. brasiliensis & 4 & 0 & 2 & 0 & 0 \\
\hline P. carotovorum subsp. carotovorum & 2 & 0 & 0 & 0 & 0 \\
\hline P. wasabiae & 12 & 0 & 0 & 7 & $11^{\mathrm{c}}$ \\
\hline
\end{tabular}

${ }^{\text {a }}$ Pectobacterium spp. detected by PCR.

${ }^{\mathrm{b}}$ PCR assay for $P$. carotovorum subsp. carotovorum cross-reacted with $P$. wasabiae.

${ }^{c} P$. wasabiae was isolated and characterized from three of these stems.

TABLE 7. Incidence of Pectobacterium spp. and subspecies detected by taxon-specific polymerase chain reaction (PCR) in stolon end tissue of individual progeny tubers harvested from the 2010 irrigated field trial

\begin{tabular}{lcccc}
\hline & & \multicolumn{2}{c}{ Tubers positive in PCR $(\%)^{\mathrm{a}}$} \\
\cline { 3 - 5 } Inoculated taxon & Number of tubers tested & Pectobacterium atrosepticum & P. carotovorum subsp. brasiliensis & P. wasabiae \\
\hline P. atrosepticum & 30 & 13 & 40 & 10 \\
P. carotovorum subsp. brasiliensis & 20 & 0 & 30 & 25 \\
P. carotovorum subsp. carotovorum & 20 & 20 & 23 & 30 \\
P. wasabiae & 30 & 7 & 30 & 10 \\
Control (water) & 10 & 0 & 30 & \\
\hline
\end{tabular}

a Pectobacterium spp. detected by PCR. 
detection tools also provides an opportunity to assess the presence of multiple bacteria in complex environments without the need for isolation. The availability of taxon-specific PCR assays for the Pectobacterium spp. allowed evaluation of the mixture of Pectobacterium spp. present in decayed potato tissue. The specificity of the PCR assays using the $P$. atrosepticum and $P$. carotovorum subsp. brasiliensis primers were confirmed in preliminary PCR tests on characterized pure cultures. Specificity of PCR with the $P$. carotovorum subsp. carotovorum primer pair was more limited because they also amplified the expected 550bp product from some strains identified as $P$. wasabiae (25) and did not amplify DNA from other strains that were identified as $P$. carotovourm subsp. carotovorum on the basis of biochemical tests. The isolation of $P$. wasabiae strains early on in this study necessitated the development of a specific primer set for this species and was accomplished using GenBank sequences of the phytase gene (44). Subsequently, a new P. wasabiae-specific PCR assay using newly designed primers based on the YD repeat protein gene was published (27). Specificity of these primers (PW7011F/R) was identical to those of the phytase-directed primers designed in this study when compared in tests with pure culture and sample DNA.

The presence of multiple Pectobacterium spp. in potato, even in the same plant, has been noted previously $(26,31)$. In our study, we specifically targeted potato stems with typical blackleg symptoms and, although most stems were positive for $P$. atrosepticum in $\mathrm{PCR}$, as expected if this species continues to be the main cause of potato blackleg in Canada, in only one-half of the stems was it the only Pectobacterium sp. detected. Interestingly, $P$. wasabiae was detected as the only Pectobacterium sp. present in several stems but was also present most frequently in combination with $P$. atrosepticum. Additionally, $P$. carotovorum subsp. carotovorum and, occasionally, $P$. carotovorum subsp. brasiliensis were detected in stems along with $P$. atrosepticum or $P$. wasabiae. Although the Pectobacterium spp. or subspecies isolated from symptomatic blackleg stems, with one exception, were among those that had been detected by PCR in the same samples, the molecular approach to evaluating the microbial populations revealed a more complex soft-rotting microbial population than is usually evident from evaluations based on isolation alone. The presence of multiple Pectobacterium spp. in diseased plants raises the specter of synergism among genotypes that might exacerbate incidence or severity of disease. The question of synergistic activity among the pectolytic bacteria is yet to be fully addressed but, in a preliminary experiment in which both $P$. atrosepticum and $P$. wasabiae were vacuum inoculated into seed tubers, disease incidence in the subsequent plant stand was not greater than when either pathogen was inoculated alone (unpublished observation).

P. wasabiae was previously implicated as a cause of potato tuber rots in New Zealand, Iran, and Wisconsin and was shown to have capacity for causing decay lesions in stems upon artificial inoculation $(1,31,39)$; however, this study is the first to show that it is also a causal agent of a blackleg-like disease in potato. $P$. wasabiae was isolated as the sole Pectobacterium sp. from a number of potato stems expressing typical blackleg symptoms collected from commercial potato fields. Inoculation of greenhouse-grown plants confirmed its capacity to cause stem decay and, in field trials, $P$. wasabiae-inoculated tubers developed plants with typical blackleg symptoms. Detection in and reisolation from diseased stems fulfilled Koch's postulates for confirming disease etiology. The vacuum infiltration method of inoculating seed potato tubers with Pectobacterium spp. simulated natural tuber contamination and served to show that $P$. wasabiae induced stem disease from tuber-borne inoculum under agricultural field conditions apart from causing stem decay lesions from artificial inoculation of aboveground tissue. A similar tuber vacuum infiltration strategy was used to show that some strains of P. caro- tovorum subsp. carotovorum also causes blackleg in potato under temperate climatic conditions (14).

The Canadian isolates of $P$. carotovorum subsp. brasiliensis were clearly less virulent as a potato stem pathogen than isolates of $P$. atrosepticum and $P$. wasabiae. Although a few plants grown from $P$. carotovorum subsp. brasiliensis-inoculated seed tubers developed blackleg-like symptoms, $P$. carotovorum subsp. brasiliensis could not be isolated from these stems. The low level of virulence exhibited by our $P$. carotovorum subsp. brasiliensis isolates contrasts with the high virulence of the Brazilian isolates (15). Although our isolates of P. carotovorum subsp. brasiliensis, along with those obtained in Wisconsin (31), formed a novel clade in MLST dendrograms with strains from Brazil, they did differ from the Brazilian strains in that they did not produce acid from $\alpha$-methylglucoside or reducing substances from sucrose. It is evident that virulence characteristics may be quite unrelated to taxonomic placement, and unsurprisingly so, as pointed out by others (55), because modern bacterial taxonomy increasingly relies on the nucleotide sequence of various genomic loci such as 16S rRNA genes and housekeeping genes, chromosomal regions quite separate from pathogenicity and virulence genes. Moreover, tuber maceration ability, although a characteristic of all the Pectobacterium strains, also varied in aggressiveness among strains of the same species or subspecies and was not correlated with blackleg virulence. These results are consistent with those of Kim et al. (26), who also found that there was no correlation between maceration ability and possession of a purported pathogenicity factor, the type III secretion system.

The migration of $P$. atrosepticum bacteria into progeny tubers via the stolons has been a hallmark of the blackleg disease. In this article, we provide experimental evidence that $P$. wasabiae and $P$. carotovorum subsp. brasiliensis also occur in the stolon attachment site of progeny tubers developing on plants grown from inoculated seed tubers. Infection of progeny tubers via stolons is an important means by which $P$. atrosepticum is known to be propagated from one generation of potato production to the next, whereas field inoculum is considered unimportant because the species survives poorly in the soil environment and is not known to be associated with weed hosts or to persist in other environmental niches. This may be different for $P$. carotovorum subsp. brasiliensis and $P$. wasabiae. The capacity of these species to persist in the field environment has not been studied to any extent but, if their environmental survival capacity is greater than that of $P$. atrosepticum such as $P$. carotovorum subsp. carotovorum, they potentially could also colonize potato plants directly from soil inoculum reservoirs, as was elegantly demonstrated for Dickeya spp. recently (5).

The persistence and behavior of bacteria in the field environment has consequences for disease control strategies. Whether or not plant-pathogenic bacteria persist in soil between growing seasons, survive in association with weed plants, are present in irrigation water, or are readily dispersed in atmospheric aerosols will have consequences for the success of disease control strategies that utilize pathogen-tested minitubers or aseptic tissue cultures to initiate each cycle of seed potato propagation. The rate of contamination with Pectobacterium spp. once the potato tubers are planted in the field is, in part, a function of the capacity of the bacteria to persist in the environment, as well as its propensity to spread through contamination of agricultural equipment (55). Moreover, the capacity of pectolytic bacteria to survive on stored seed potato tubers and their optimum temperature for initiation of soft rot lesions will affect the storability of crops and management practices for minimizing storage loss. The deliberate strategies for controlling blackleg caused by $P$. atrosepticum, supported by a large number of studies published in the scientific literature and promulgated in extension publications, may not be directly applicable for controlling diseases caused by $P$. carotovorum subsp. brasiliensis or P. wasabiae. To avoid confusion and mis- 
application of information pertaining specifically to $P$. atrosepticum-caused blackleg, it is suggested that use of the blackleg name for the diseases caused by $P$. carotovorum subsp. brasiliensis, $P$. carotovorum subsp. carotovorum, and $P$. wasabiae be avoided despite the similar symptomologies. Rather, all bacterial rots of potato stems could more appropriately be designated under a single name such as "bacterial stem rot". The bacterial stem rot nomenclature can equally well accommodate potato stem rots caused by the various Dickeya spp. as it can accommodate stem rots caused by Pectobacterium spp. because all have overlapping symptomologies (55). A previous recommendation (38) that all potato stem rots be named "blackleg" to facilitate visual disease rating by crop inspectors as a requirement for seed potato certification programs blurs the fact that much of what has been written in the past about blackleg refers specifically to disease caused by $P$. atrosepticum. Coining a new functional term for all bacterial stem rots of potato, including blackleg and diseases with similar symptoms, facilitates the terminology for inspectors and producers.

This study confirmed that $P$. atrosepticum remains the most important causal agent of blackleg disease in Canada, similar to results in Finland, where $P$. atrosepticum remains the major cause of blackleg despite the increasingly common presence of Dickeya spp. in potato stocks (28). In other parts of Western Europe, New Zealand, Brazil, and South Africa, P. atrosepticum is no longer or perhaps never was the primary cause of potato blackleg. The shift in potato stem rot etiology from a disease caused by essentially a single serotype of the one species, $P$. atrosepticum, to a disease syndrome involving several distinct taxa of soft-rotting bacteria, as observed in this study, is quite remarkable but not as dramatic as the shift in Western Europe, where potato stem rot is now almost entirely due to Dickeya spp. $(6,55)$. In both North America and Western Europe, this etiological shift follows an extended period of approximately 30 years during which significant changes in the potato industry also took place. In the past, seed potato tubers were grown from clonally selected field tubers on which a stable microbial community was maintained and passed on from one generation of potato production to the next. Populations of specific genotypes of $P$. atrosepticum and $P$. carotovorum subsp. carotovorum, well adapted to the potato biosphere, were most frequently associated with the potato crop. Serogroup I was, by far, the most predominate strain of $P$. atrosepticum, and serogroup III of $P$. carotovorum subsp. carotovorum predominated $(8,10)$. An earlier study also found that populations of Pectobacterium spp. on potato foliage that presumably were deposited from environmental sources had little impact on the make up of belowground populations in the plant root zone (8), supporting the long-held view that the best-adapted strains persist in association with host crop plants (49). Whether field temperature during the growing season or other factors determine which strains in the Pectobacterium sp. complex are best adapted to a particular crop is not known.

Today, seed potato crops are mainly initiated from minitubers propagated in protected environments from tissue culture plantlets and then multiplied for a limited number of field generations. Minitubers that are planted to produce the first field generation of seed potato are microbiologically naïve and susceptible to colonization by bacteria from the environment. The best-adapted and most competitive bacterial species have the potential of colonizing progeny tubers and remain associated with the seed crop during subsequent generations of potato production. In Canada and the United States, strains of the new-found Pectobacterium taxa, $P$. wasabiae and $P$. carotovorum subsp. brasiliensis, perhaps are sometimes among the primary colonizers of firstfield-generation seed potato. In Western Europe, Dickeya spp. is an important primary colonizer of microbiologically naïve earlygeneration potato seed stocks (55). More recently, the so-called D. solani strain, which is very closely related to a strain occurring on hyacinth in the Netherlands, contaminates European seed potato crops $(7,55)$, and it is speculated that intercrop movement of specific bacterial strains occurs readily via irrigation water (7). This would explain the specific association of Dickeya spp. with seed potatoes imported from the Netherlands, where a vigorous seed potato industry thrives in close proximity to an extensive flower bulb industry $(57,58)$. In light of these observations, artificial inoculation of microbiologically naïve minitubers with a low virulence strain of $P$. carotovorum subsp. carotovorum to occupy the Pectobacterium niche of the potato biosphere may be an interesting disease control strategy to avoid colonization with more virulent or aggressive strains of other soft rot bacteria.

The fact that some strains of Pectobacterium spp. isolated more than 30 years ago from potato in both North America and Western Europe can now be identified as $P$. carotovorum subsp. brasiliensis and $P$. wasabiae (Table 4) proves that these strains are not new to potato. Although their identification has only been made possible by recent developments in molecular methods, it is also notable that their number is small in comparison with the total number of isolates evaluated. Discovery of the role that these genotypes play in potato stem rots is probably a result not only of the availability of the new tools for their identification but also of their increased frequency due to the changes in potato production practices, as described above. Whether the assortment of Pectobacterium spp. and subspecies associated with the potato crop affects the incidence of disease in the field, the susceptibility of the crop under different growing conditions due to the differences in growth condition optima, or susceptibility to decay in storage remains to be determined. Certainly, greater attention needs to be paid to strain identity and the combination of strains when studying bacterial stem rots of potato than had been previously recognized.

\section{ACKNOWLEDGMENTS}

We thank L. Kawchuk, T. Shinners-Carnelley, R. Howard, K. Merrifield, and anonymous potato inspectors for providing field samples; J. Gourley, A. Jenkins, J. Nickerson, and N. McCarville for their technical assistance; and D. Pratt and L. MacFayden of the Agriculture and AgriFood Canada Harrington Farm, PE for their assistance with the field trials.

\section{LITERATURE CITED}

1. Baghaee-Ravari, S., Rahimian, H., Shams-Bakhsh, M., Lopez-Solanilla, E., Antunez-Lamas, M., and Rodriguez-Palenzuela, P. 2011. Characterization of Pectobacterium species from Iran using biochemical and molecular methods. Eur. J. Plant Pathol. 129:413-425.

2. Bastas, K. K., Hekimhan, H., Maden, S., and Tor, M. 2009. First report of bacterial stalk and head rot disease caused by Pectobacterium atrosepticum on sunflower in Turkey. Plant Dis. 93:1352.

3. Cother, E. J. 1980. Bacterial seed tuber decay in irrigated sandy soils of New South Wales. Potato Res. 23:75-84.

4. Cuppels, D. A., and Kelman, A. 1974. Evaluation of selective media for isolation of soft-rot bacteria from soil and plant tissue. Phytopathology 64:468-475.

5. Czajkowski, R., de Boer, W. J., Velvis, H., and van der Wolf, J. M. 2010. Systemic colonization of potato plants by a soilborne, green fluorescent protein-tagged strain of Dickeya sp. biovar 3. Phytopathology 100:11341142.

6. Czajkowski, R., Grabe, G. J., and van der Wolf, J. M. 2009. Distribution of Dickeya spp. and Pectobacterium carotovorum subsp. carotovorum in naturally infected seed potatoes. Eur. J. Plant Pathol. 125:263-275.

7. Czajkowski, R., Perombelon, M. C. M., van Veen, J. H. A., and van der Wolf, J. M. 2011. Control of blackleg and tuber soft rot of potato caused by Pectobacterium and Dickeya species: A review. Plant Pathol. 60:9991013.

8. De Boer, S. H. 1983. Frequency and distribution of Erwinia cartovora serogroups associated with potato in the Pemberton Valley of British Columbia. Can. J. Plant Pathol. 5:279-284.

9. De Boer, S. H. 2003. Characterization of pectolytic erwnias as highly sophisticated pathogens of plants. Eur. J. Plant Pathol. 109:893-899.

10. De Boer, S. H., Copeman, R. J., and Vruggink, H. 1979. Serogroups of 
Erwinia carotovora potato strains determined with diffusible somatic antigens. Phytopathology 69:316-319.

11. De Boer, S. H., and Sasser, M. 1986. Differentiation of Erwinia carotovora subsp. carotovora and E. carotrovora subsp. atroseptica on the basis of cellular fatty acid composition. Can. J. Microbiol. 32:796800.

12. De Boer, S. H., Verdonck, L., Vruggink, H., Harju, P., Bang, H. O., and De Ley, J. 1987. Serological variation among potato blackleg causing Erwinia carotovora subsp. atroseptica strains. J. Appl. Bacteriol. 63:487495.

13. De Boer, S. H., and Ward, L. J. 1995. PCR detection of Erwinia caotovora subsp. atroseptica associated with potato tissue. Phytopathology 85:854-858.

14. de Haan, E. G., Dekker-Nooren, T. C. E. M., van den Bovenkamp, G. W., Speksnijder, A. G. C. L., van der Zouwen, P. S., and van der Wolf, J. M. 2008. Pectobacterium carotovorum subsp. carotovorum can cause potato blackleg in temperate climates. Eur. J. Plant Pathol. 122:561-569.

15. Duarte, V., De Boer, S. H., Ward, L. J., and de Oliveira, A. M. R. 2004. Characterization of atypical Erwinia carotovora strains causing blackleg of potato in Brazil. J. Appl. Microbiol. 96:535-545.

16. El Tassa, S. O. M., and Duarte, V. 2004. Ocorrencia de pectobacterias em tubreculos de batata-semente no estado do Rio Grande so Sul. Fitopatol. Bras. 29:620-625.

17. Fucikovsky, L, Rodriguez, M., and Cartin, L. 1978. Soft rot bacteria from plants and insects. Pages 603-607 in: Proc. Int. Conf. Plant Pathog. Bact. Gibert-Claraey, Tours, France.

18. Gardan, L., Gouy, C., Christen, R., and Samson, R. 2003. Elevation of three subspecies of Pectobacterium carotovorum to species level: Pectobacterium atrosepticum sp. nov., Pectobacterium betavasculorum sp. nov. and Pectobacterium wasabiae sp. nov. Int. J. Syst. Evol. Microbiol. 53:381-391.

19. Glasner, J. D., Marquez-Villavicencio, M., Kim, H. S., Jahn, C. E., Ma, B., Biehl, B. S., Rissman, A. I., Mole, B., Yi, X., Yang, C. H., Dangl, J. L., Grant, S. R., Perna, N. T., and Charkowski, A. O. 2008. Niche-specificity and the variable fraction of the Pectobacterium pan-genome. Mol. PlantMicrobe Interact. 21:1549-1530.

20. Graham, D. C. 1976. Re-infection by Erwinia carotovora (Jones) Bergey et al. in potato stocks derived from stem cuttings. EPPO Bull. 4:243-245.

21. Graham, D. C., and Hardie, J. L. 1971. Prospects for control of potato blackleg disease by the use of stem cuttings. Page 219-224 in: Proc. 6th Br. Insectic. Fungic. Conf. British Crop Protection Council, UK.

22. Graham, D. C., Quinn, C. E., and Harrison, M. D. 1976. Recurrence of soft rot coliform bacterial infections in potato stem cuttings: an epidemiological study on the central nuclear stock production farm in Scotland 1967-74. Potato Res. 19:3-20.

23. Goto, M., and Matsumoto, K. 1987. Erwinia carotovora subsp. wasabiae subsp. nov. isolated from diseased rhizomes and fibrous roots of Japanese horseradish (Eutrema wasabi Maxim.). Int. J. Syst. Bacteriol. 37:130-135.

24. Helias, V. 2006. Potato Blackleg in France: Incidence of Causal Erwinia Species and Field Symptoms Expression. Int. Erwinia Workshop, Dundee, Scotland.

25. Kang, H. W., Kwon, S. W., and Go, S. J. 2003. PCR-based specific and sensitive detection of Pectobacterium carotovorum ssp. carotovorum by primers generated from a URP-PCR fingerprinting-derived polymorphic band. Plant Pathol. 52:127-133.

26. Kim, H.-S., Ma, B, Perna, N. T., and Charkowski, A. M. 2009. Phylogeny and virulence of naturally occurring type III secretion system-deficient Pectobacterium strains. Appl. Environ. Microbiol. 75:4539-4549.

27. Kim, M. H., Cho, M. S, Kim, B. K, Choi, H. J., Hahn, J. H., Kim, C. K, Cang, M. J., Kim, S. H., and Park, D. S. 2012. Quantitative real-time polymerase chain reaction assay for detection of Pectobacterium wasabiae using YD repeat protein gene-based primers. Plant Dis. 96:253257.

28. Laurila, J., Ahola, V., Lehtinen, A., Joutsjoki, T., Hannukkala, A., Rahdonen, A., and Pirhonen, M. 2008. Characterization of Dickeya strains isolated from potato and river water samples in Finland. Eur. J. Plant Pathol. 122:213-225.

29. Laurila, J., Hannukkala, A., Nykyri, J., Pasanen, M., Helias, V., Garlant, L., and Pirhonen, M. 2010. Symptoms and yield reduction caused by Dickeya spp. strains isolated from potato and river water in Finland. Eur. J. Plant Pathol. 126:249-262.

30. Lumb, V. M., Perombelon, M. C. M., and Zutra, D. 1986. Studies of a wilt disease of the potato plant in Israel caused by Erwinia chrysanthemi. Plant Pathol. 35:196-202.

31. Ma, B., Hibbing, M. E., Kim, H.-S., Reedy, R. M., Yedidia, I, Breuer, J, Breuer, J., Glasner, J. D., Perna, N. T., Kelman, A., and Charkowski, A. O. 2007. Host range and molecular phylogenies of the soft rot enterobacterial genera Pectobacterium and Dickeya. Phytopathology 97:1150-1163.

32. Malathrakis, N. E., and Goumas, D. E. 1987. Bacterial soft rot of tomato in plastic greenhouses in Crete. Ann. Appl. Biol. 111:115-123.
33. Molina, J. J., and Harrison, M. D. 1977. The role of Erwinia carotovora in potato blackleg. I. Relationship of E. carotovora var. carotovora and E. carotovora var. atroseptica in potato blackleg in Colorado. Am. Potato J. 54:587-591.

34. Molina, J. J., and Harrison, M. D. 1980. The role of Erwinia carotovora in the epidemiology of potato blackleg. II. The effect of soil temperature on disease severity. Am. Potato J. 57:351-363.

35. Nassar, A., Darrasse, A., Lemattre, M., Kotoujansky, A., Dervin, C., Vedel, R., and Bertheau, Y. 1996. Characterization of Erwinia chrysanthemi by pectinolytic isozyme polymorphism and restriction fragment length polymorphism analysis of PCR-amplified fragments of pel genes. Appl. Environ. Microbiol. 62:2228-2235.

36. Palacio-Bielsa, A., Cambra, M. A., and Lopez, M. M. 2006. Characterisation of potato isolates of Dickeya chrysanthemi in Spain by a microtitre system for biovar determination. Ann. Appl. Biol. 148:157-164.

37. Palacio-Bielsa, A., Rodriguez Mosquera, M. E., Cambra Alvarez, M. A., Berruete Rodriguea, I. M., Lopez Solanilla, E., and Rodriguez Palenzuela, P. 2010. Phenotypic diversity, host range and molecular phylogeny of Dickeya isolates from Spain. Eur. J. Plant Pathol. 127:311-324.

38. Perombelon, M. C. M., and Kelman, A. 1987. Blackleg and other potato diseases caused by soft rot erwinias: proposal for revision of terminology. Plant Dis. 71:283-285.

39. Pitman, A. R., Harrow, S. A., and Visnovsky, S. B. 2010. Genetic characterisation of Pectobacterium wasabiae causing soft rot disease of potato in New Zealand. Eur. J. Plant Pathol. 126:423-435.

40. Pitman, A. R., Wright, P. J., Galbraith, M. D., and Harrow, S. A. 2008. Biochemical and genetic diversity of pectolytic enterobacteria causing soft rot disease of potatoes in New Zealand. Australas. Plant Pathol. 37:559-568.

41. Samson, R., Foutier, F., Sailly, M., and Jouan, B. 1987. Caracterisation des Erwinia chrysanthemi isolees de Solanum tuberosum et d'autres plantes-hotes selon les biovars et serogroupes. EPPO Bull. 17:11-16.

42. Schaad, N. W., Jones, J. B., and Chun, W. 2001. Laboratory Guide for Identification of Plant Pathogenic Bacteria, 3rd ed. American Phytopathological Society Press, St. Paul, MN.

43. Serfontein, S., Logan, C., Swanepoel, A. E., Boelema, B. H., and Theron, D. J. 1991. A potato wilt disease in South Africa caused by Erwinia carotovora subspecies carotovora and E. chyrsanthemi. Plant Pathol. 40:382-386.

44. Shao, N., Huang, H., Meng, K, Luo, H., Wang, Y, Yang, P., and Yao, B. 2008. Cloning, expression, and characterization of a new phytase from the phytopathogenic bacterium Pectobacterium wasabiae DSMZ 18074. J. Microbiol. Biotechnol. 18:1221-1226.

45. Slawiak, M., Lojkowska, E., and van der Wolf, J. M. 2009. First report of bacterial soft rot on potato caused by Dickeya sp. (syn. Erwinia chrysanthemi) in Poland. Plant Pathol. 58:794.

46. Slawiak, M., van Beckhoven, J. R. C. M., Speksnijder, A. G. C. L., Czajkowski, R., Grabe, G., and van der Wolf, J. M. 2009. Biochemical and genetical analysis reveal a new clade of biovar 3 Dickeya spp. strains isolated from potato in Europe. Eur. J. Plant Pathol. 125:245-261.

47. Sledz, W., Jafra, S., Waleron, M., and Lojkowska, E. 2000. Genetic diversity of Erwinia carotovora strains isolated from infected plants grown in Poland. EPPO Bull. 30:403-407.

48. Stanghellini, M. E., and Meneley, J. C. 1975. Identification of soft-rot Erwinia associated with blackleg in Arizona. Phytopathology 65:86-87.

49. Stanghellini, M. E., Sands, D. C., Kronland, W. C., and Mendonca, M. M. 1977. Serological and physiological differentiation among isolates of Erwinia carotovora from potato and sugarbeet. Phytopathology 67:11781182.

50. Stommel, J. R. Goth, R. W., and Haynes, K. G. 1996. Pepper (Capsicum annuum) soft rot caused by Erwinia carotovora subsp. atroseptica. Plant Dis. 80:1109-1112.

51. Tanii, A., and Akai, J. 1975. Blackleg of potato plant caused by a serologically specific strain of Erwinia carotovora var. carotovora (Jones) Dye. Ann. Phytopathol. Soc. Jpn. 41:513-517.

52. Thomson, S. V., Hildebrand, D. C., and Schroth, M. N. 1981. Identification and nutritional differentiation of the Erwinia sugar beet pathogen from members of Erwinia carotovora and Erwinia chrysanthemi. Phytopathology 71:1037-1042.

53. Tominaga, T., and Ogasawara, K. 1979. Bacterial stem rot of potato caused by Erwinia chrysanthemi. Ann. Phytopathol. Soc. Jpn. 45:474477.

54. Toth, I. K., Bertheau, Y., Hyman, L. J., Laplaze, L., Lopez, M. M., McNicol, J., Niepold, F., Persson, P., Salmond, G. P. C., Sletten, A., van der Wolf, J. M., and Perombelon, M. C. M. 1999. Evaluation of phenotypic and molecular typing techniques for determining diversity in Erwinia carotovora subsp. atroseptica. J. Appl. Microbiol. 87: $770-781$

55. Toth, I. K., van der Wolf, J. M., Saddler, G., Lojkowska, E., Helias, V., Pirhonen, M, Tsror (Lahkim), L., and Elphinstone, J. G. 2011. Dickeya 
species: an emerging problem for potato production in Europe. Plant Pathol. 60:385-399.

56. Trujillo, G, Hernandez, Y., and Munoz, C. 2000. Tobacco seed beds affected by Erwinia carotovora subsp. atroseptica at the Cojedes state, Venezuela. Rev. Fac. Agron. Univ. Cent. Venez. 26:27-38.

57. Tsror (Lahkim), L., Erlich, O., Hazanovsky, M., Ben Daniel, B., Zig, U., and Lebiush, S. 2012. Detection of Dickeya spp. latent infection in potato seed tubers using PCR or ELISA and correlation with disease incidence in commercial field crops under hot-climate conditions. Plant Pathol. 61:161-168.

58. Tsror (Lahkim), L., Erlich, O., Leblush, S., Hazanovsky, M., Zig, U., Slawiak, M, Grabe, G., van der Wolf, J. M., and van de Haar, J. J. 2009. Assessment of recent outbreaks of Dickeya sp. (syn. Erwinia chrysanthemi) slow wilt in potato crops in Israel. Eur. J. Plant Pathol. 123:311-320.

59. van der Merwe, J. J., Coutinho, T. A., Korsten, L., and van der Waals, J. E. 2010. Pectobacterium carotovorum subsp. brasiliensis causing blackleg on potatoes in South Africa. Eur. J. Plant Pathol. 126:175-185.

60. Ward, L. J., and De Boer, S. H. 1994. Specific detection of Erwinia carotovora subsp. atroseptica with a digoxigenin-labelled DNA probe. Phytopathology 84:180-186.

61. Ward, L. J., De Boer, S. H., and Li, X. 2012. Identification and specific detection of Pectobacterium wasabiae associated with blackleg-like disease of potato. (Abstr.) Can. J. Plant Pathol. 34:348.

62. Williams, D. W. 1969. Progress in healthy seed potato production. Scot. Agric. 48:287-289. 